\title{
ANÁLISE DO APEGO AO LUGAR E REPRESENTAÇÕES SOCIAIS DA ESCOLA EM CRIANÇAS NO ÂMBITO ESCOLAR
}

\author{
ANALYSIS OF THE APPENDIX TO THE PLACE AND SOCIAL REPRESENTATIONS OF
}

THE SCHOOL IN CHILDREN IN THE SCHOOL AREA

Mariane PaveiMacan ${ }^{1}$, Amanda Castro $^{2}$

\begin{abstract}
RESUMO
Este estudo buscou compreender as representações sociais de escola e o apego ao lugar de alunos das primeiras séries do ensino fundamental, em uma escola no município de Criciúma. Para a coleta de dados utilizou-se um mapa comportamental, mapa afetivo e uma entrevista informal com 14 crianças. Estas informações foram transcritas e analisadas por meio de análise de conteúdo. Compreende-se que o meio de locomoção da criança até a escola e seus hábitos fazem com que a sua percepção ambiental aumente ou não. Ao caminhar a pé a criança consegue focar sua atenção na paisagem, nos elementos e na composição do caminho que está fazendo, fazendo com que ela tenha mais domínio do ambiente possibilitando maior auto segurança no momento que, por exemplo, ela é deixada na escola, pois ela saberá fazer o caminho de volta até a casa caso algo aconteça. A casa, em detrimento da escola apareceu com mais ênfase nos desenhos, com isso, para que favorecer identidade de lugar e para que a criança se sinta parte do ambiente precisa-se que ela forneça elementos para apropriação do espaço, para que ela possa também construir esse ambiente e se identificar.
\end{abstract}

Palavras-chave: Apego. Escola. Crianças.

\begin{abstract}
This study sought to understand the social representations of school and the attachment to the place of students of the first serious elementary school, in a school in the municipality of Criciúma. A behavioral map, affective map and an informal interview with 14 children were used to collect data. This information was transcribed and analyzed through content analysis. It is understood that the means of getting the child to school and their habits make their environmental perception increase or not. When walking, the child is able to focus his attention on the landscape, the elements and the composition of the path he / she is doing, making it more restrained in the environment, allowing greater self-confidence at the moment when, for example, it is left in school, because she'll be able to make her way home if anything happens. The house, to the detriment of the school appeared with more emphasis in the drawings, with that, so that to favor identity of place and so that the child feels part of the environment it needs that it provides elements for appropriation of the space, so that it can also build this environment and identify.
\end{abstract}

Keywords: Attachment. School. Children.

\footnotetext{
${ }^{1}$ Estudante do curso de Arquitetura da Universidade do Extremo Sul Catarinense- UNESC

${ }^{2}$ Mestra, doutoranda em Psicologia na Universidade Federal de Santa Catarina. Professora na Universidade do Extremo Sul Catarinense. Rua Rio dos Cedros, 188, apto 502. Criciúma- Santa Augusta. E-mail: amandacastrops@gmail.com
} 


\section{INTRODUÇÃO}

Segundo Moser (1998), a Psicologia Ambiental estuda o indivíduo em seu contexto, tendo como tema central as "inter-relações" entre o indivíduo e o meio ambiente físico e social. A Psicologia Ambiental ressalta a relação bidirecional entre o indivíduo e ambiente, priorizando aspectos físicos do ambiente como: barulho, conforto térmico, arranjo espacial, dentre outros. Estes aspectos atuam sobre o comportamento humano em interdependência com os demais elementos, físicos e humanos, de um determinado contexto ambiental (Campos-de-Carvalho, 1993; Proshansky e cols.,1970; Rivlin, 2003; Stokols, 1978).

Dentre os conceitos da psicologia social, os que serão utilizados no âmbito desse trabalho são: Apego ao Lugar e Representações sociais. O apego ao lugar pode ser definido como a conexão emocional firmada com cenários físicos, envolvendo sentimentos derivados da experiência espacial real ou esperada (Brown \& Perkins, 1992; Giuliani, 2004; Shumaker \& Taylor, 1983).

E sobre as representações sociais, esta "É uma forma de conhecimento socialmente elaborada e partilhada, tendo uma orientação prática e concorrendo para a construção de uma realidade comum a um conjunto social" (Jodelet,1989, p.36).

Tendo em vista que tais conceitos serão aplicados em espaço escolar, para compreendermos o ambiente da escola pode-se utilizar Cooper (1981) em uma revisão da política de educação constatou que as escolas são geralmente projetadas de acordo comum a arquitetura determinista, ou seja, se acredita que o seu "design" determina como o espaço da escola deve ser usado, ficando, a cargo dos professores, dirigir o uso desses espaços seguindo os princípios das escolas.

Segundo Moran (2000), existem duas razões para se estudar a infraestrutura da escola, a primeira trata das condições físicas de trabalho, diz respeito aos meios disponíveis para um trabalho mais confortável, menos desgastante, mais prazeroso, mais produtivo e saudável para o trabalhador. A segunda razão é a de que estamos falando de educação, um trabalho de importância inegável, afinal melhor infraestrutura está relacionada com melhor qualidade do ensino.

De acordo com Davis,

(...) O espaço escolar não é apenas um continente, um recipiente que abriga alunos, livros, professores, um local em que se realizam atividades de aprendizagem. Mas é também um conteúdo, ele mesmo educativo. Escola é mais do que 4 paredes, é 
clima, espirito de trabalho, produção de aprendizagem, relações sociais de formação de pessoas. O espaço tem que gerar ideias, sentimentos, movimentos no sentido da busca do conhecimento, tem que despertar interesse em aprender, além de ser algo alegre, aprazível e confortável, tem que ser pedagógico. $\mathrm{O}$ aluno aprende dele lições sobre a relação entre corpo e a mente, o movimento e o pensamento, o silencio e o barulho do trabalho que constroem conhecimento. (DAVIS, 1993, P.53)

Portanto, para entender as inter-relações entre o indivíduo e o meio, serão utilizados os conceitos de apego ao lugar e representações sociais no âmbito escolar, por isso precisa-se verificar também o modelo escolar e sua infraestrutura, ambos influenciam diretamente nas relações e na aprendizagem.

\section{MÉTODO}

Esta pesquisa de campo é caracterizada como exploratória-descritiva e de caráter qualitativo, cujo intuito visa compreender, de forma adequada, o fenômeno estudado, para fins de produção de conhecimento científico. Trata-se de um estudo descritivo com 14 crianças que se encontram no ensino fundamental com idades de 07 a 08 anos. Devido ao critério de acessibilidade, bem como o apego ao lugar no universo infantil foi escolhido essa população para a pesquisa. A escola é escolhida, pois a criança passa maior parte de sua vida nesse grupo.

As técnicas escolhidas têm como o objetivo analisar o apego ao lugar e as representações sociais, para isso, serão utilizados dois métodos: a) Mapas afetivos: recurso que objetivou demonstrar como se revelam suas lembranças e de que forma elas são transportadas para o papel em desenhos. b) Em falas a partir da história oral e; c) Mapeamento Comportamental, através de representação gráfica das localizações e comportamentos do indivíduo no espaço, por meio de observação in loco.

\section{RESULTADOS E DISCUSSÃO}

Inicialmente no dia 16 de maio de 2018 às 9 h20min da manhã foi realizado mapeamento comportamental. O mapa comportamental é uma representação gráfica dos comportamentos e localizações das pessoas em um determinado espaço. A aplicação do mapa se dá em: (a) um diagrama representando a área observada; (b) uma definição clara dos comportamentos observados; (c) um esquema das vezes em que deve ocorrer o registro das observações; (d) um procedimento sistemático de observação. (ITTELSON, RIVLIN, PROSHANSKY, 1970). 
O espaço escolhido foi a Escola de Ensino Básico Augusto Pavei, especificamente a área externa (pátio), ocupada pelos alunos durante o recreio. A duração da observação e do mapeamento comportamental foi de 30min e a ocupação de espaço se deu conforme a figura abaixo.

Figura 01 - Mapeamento Comportamental

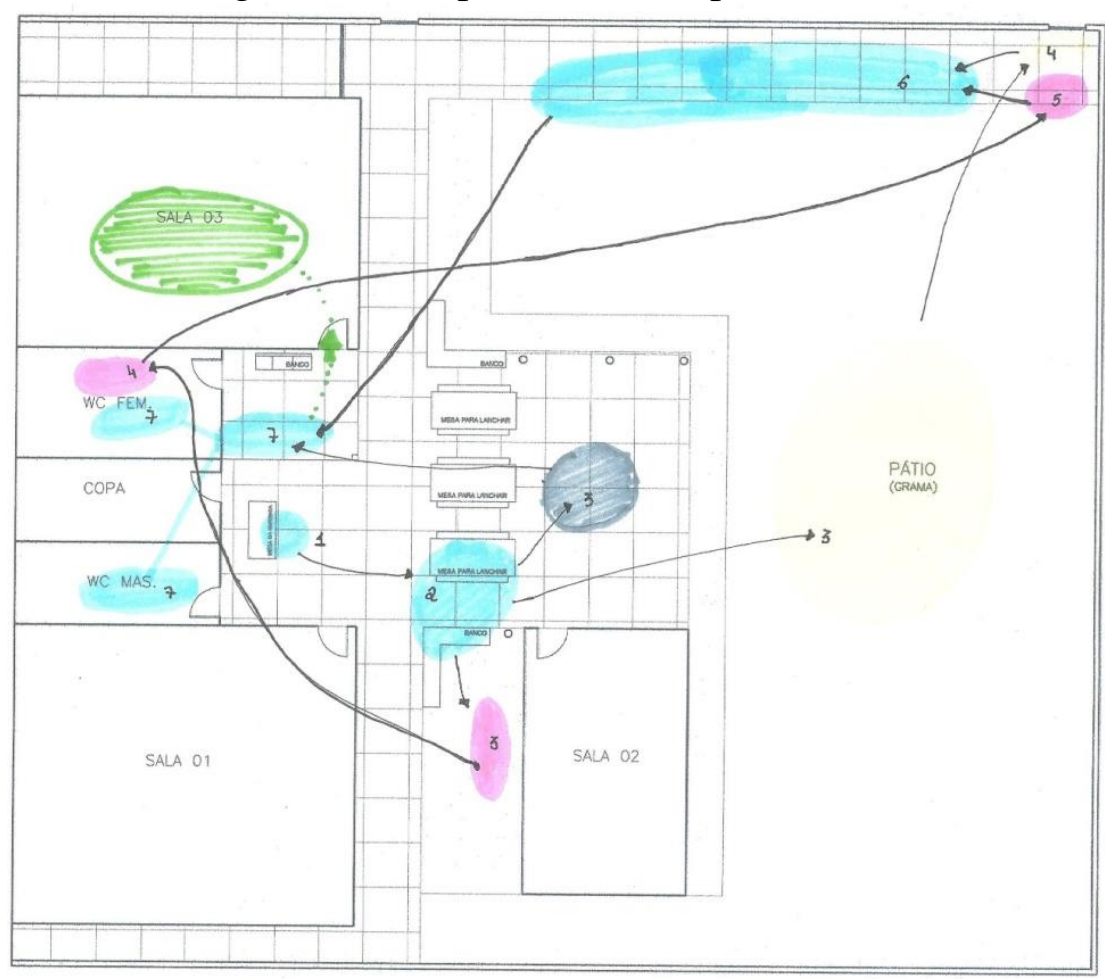

Fonte: Das autoras.

No primeiro momento os alunos se dirigiram a merendeira e depois a mesa para o lanche, possivelmente porque o tempo de lanche corresponde a 10min. Então é necessário fazer o lanche primeiro, depois ir brincar. Segundo Cordioli e Teruchkin (2007), o transtorno de ansiedade vem se instalar pela vivência repetitiva de experiências estressantes e/ou traumáticas ou pela aprendizagem de crenças fóbicas ou pela imitação de comportamentos que transmitem uma percepção negativa do mundo e do outro, que são vistos como uma permanente ameaça. Com isso, ao repetir diariamente esse momento de ir lanchar e ter apenas 10min para realizar o lanche possibilita a criança desenvolver ansiedade frente a momentos que tem tempo limitado para aproveitar.

$\mathrm{Na}$ disposição do lanche percebe-se que todos ficam em uma única mesa com a observação do professor. A disposição da turma em uma única mesa pode fortalecer seus vínculos, dando um senso de grupo a turma. Segundo Sommer (1973), cadeiras dispostas em 
círculo sugerem que ocorrerá uma discussão na qual é esperada a participação de todos; carteiras enfileiradas voltadas para o professor pressupõem aula expositiva; mesas próximas entre si formando blocos maiores indicam a realização de trabalhos em grupos, e assim por diante. Além disso, a disposição da mobília e as condições ambientais da classe podem refletir-se em fatores tão diversos quanto a sociabilidade dos usuários e seu desempenho acadêmico.

Figura 02- Pátio área coberta

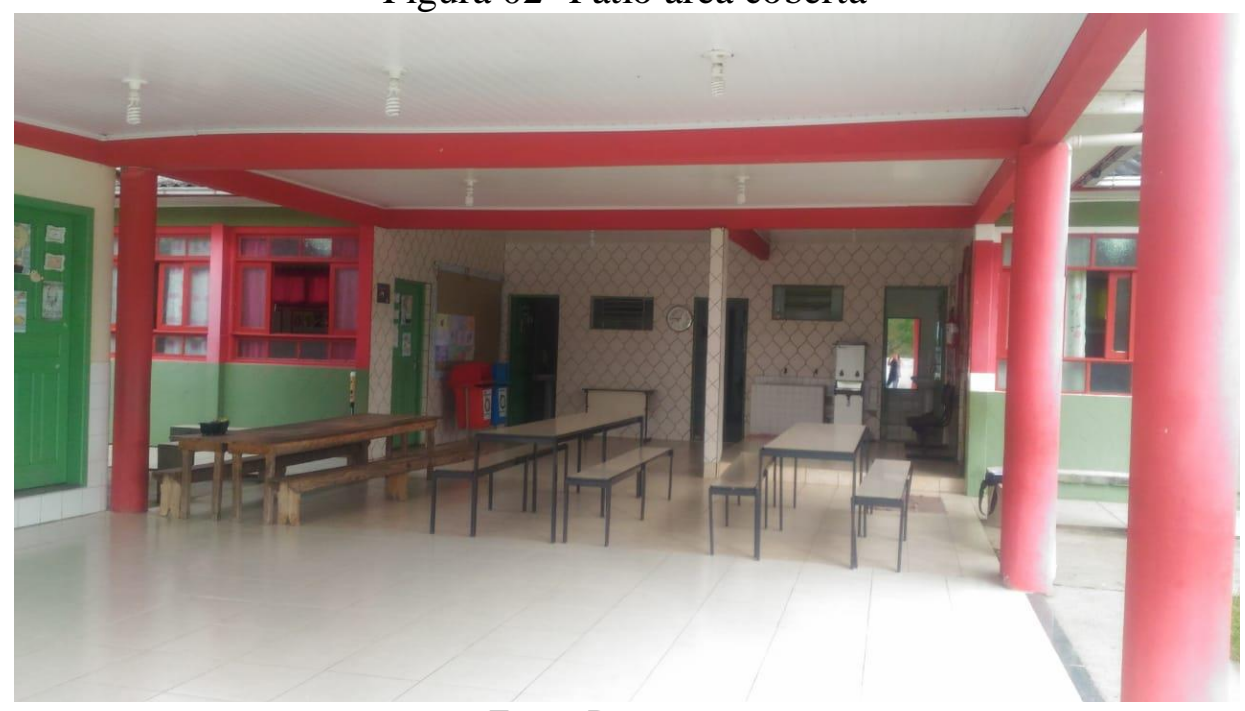

Fonte: Das autoras.

Após o lanche houve a dispersão de alunos, alguns foram para o corredor e conversam em pé durante certa de $2 \mathrm{~min}$, esse corredor é vazio e as meninas ficaram conversando de pé, pode-se pensar na alocação de bancos, mesinhas para dar qualidade ao espaço utilizado. E depois junto com suas colegas foram ao banheiro ficar brincando em frente ao espelho aproximadamente $2 \mathrm{~min}$ ). 


\section{ANÁLISE DO APEGO AO LUGAR E REPRESENTAÇÕES SOCIAIS DA ESCOLA EM CRIANÇAS NO ÂMBITO ESCOLAR}

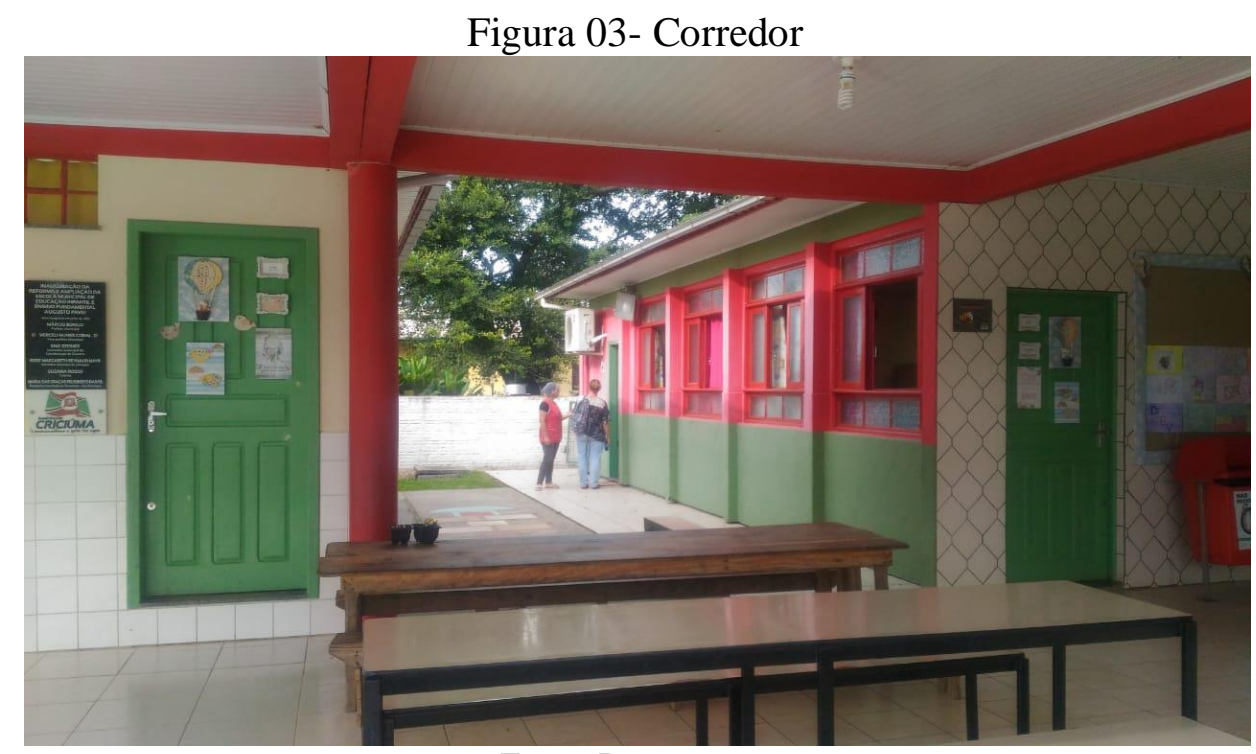

Fonte: Das autoras.

Lacan (1998) descreve o estádio do espelho como metáfora da alienação, na medida em que que a constituição do sujeito depende fundamentalmente do "Outro" desejante, para diferenciá-lo do [futuro] objeto de demanda, escrito "o" (minúscula), que representará a demanda consciente, que metaforiza e metonimiza o desejo inconsciente). O objeto metafórico/metonímico será grafado por Lacan com minúscula (“o" de “outro").

E é preciso acrescentar que o estágio do espelho se refere ao desejo (expresso pelo olhar, pelo toque, pela voz) dos protagonistas do campo desejante, e não ao espelho propriamente dito. Caso contrário não se entenderia como a criança cega passaria pelo 'estádio do espelho'. O elemento central no estádio do espelho é a predominância, no discurso do campo desejante, da separação: "Você e eu não somos o mesmo ser. Você tem um corpo (uma identidade) diferenciado do meu (da minha identidade) “.

Entende-se então que o espelho tem relação direta com o conhecimento do próprio corpo do ser, da identidade individual da criança, fazendo-a se sentir única e diferente dos outros.

Outros foram para a grama jogar bola durante $5 \mathrm{~min}$, entretanto quando os outros colegas de outras turmas chegaram foram embora, o que parece ter a existência de subgrupos a partir das salas de aula. E algumas crianças preferiram ficar no piso brincando de lego até o recreio acabar. A crianças depois de jogar bola foram para perto do muro observar a estrada. O muro pode representar as crianças um elemento de territorialidade, fazendo com que a crianças sinta que está no controle de onde ela está. 
Figura 04- Pátio

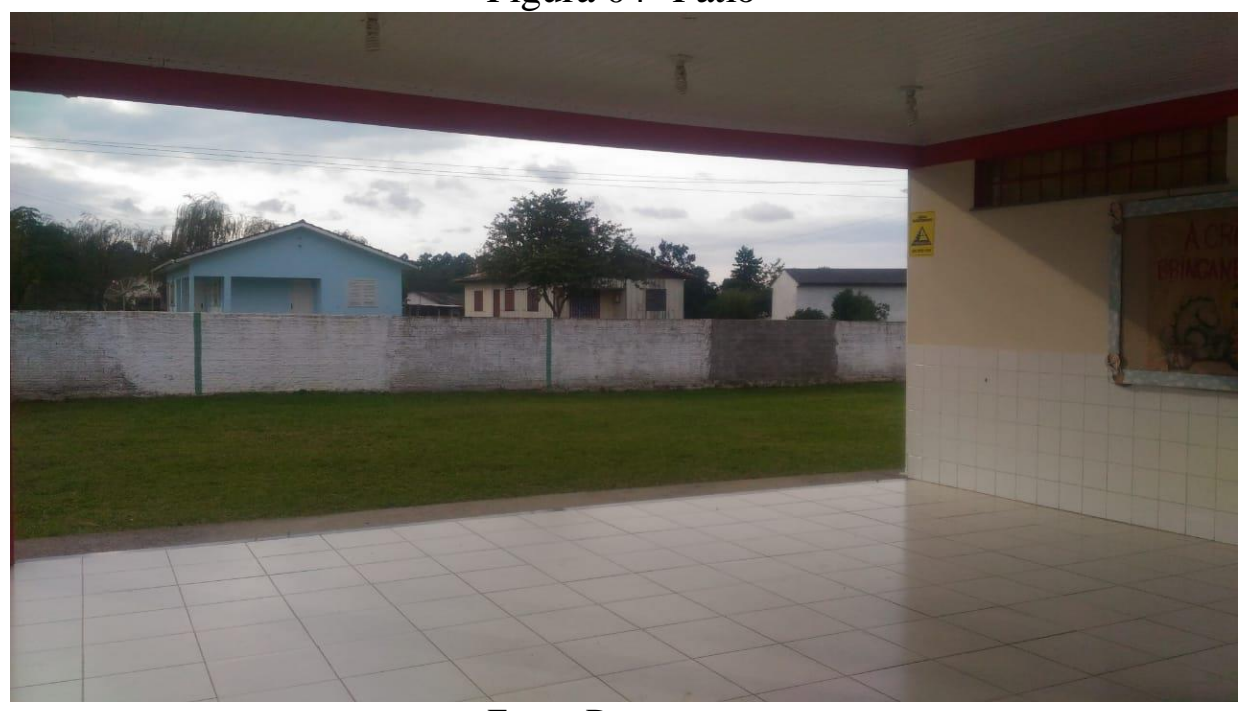

Fonte: Das autoras.

A territorialidade é uma necessidade do indivíduo de ter o seu espaço e de manter o controle sobre ele. No caso de uma residência os muros determinam o limite de seu domínio e qualquer ação relacionada com a penetração nesse território sem um convite é sentida como uma invasão à sua intimidade. (MELO, 1991) O espaço pessoal é definido como um espaço imaginário ao redor do indivíduo, necessário para manter sua privacidade e seu apropriado nível de intimidade (ALTMAN, 1975).

Logo depois chegaram as meninas que fizeram a mesma coisa que eles. Após isso todos se juntaram e foram brincar de pega-pega durante aproximadamente 4 min no corredor ao lado do muro. Este espaço (o corredor de piso) foi o espaço mais utilizado pelas crianças e por mais tempo. As crianças se aproximando do muro pode significar um afastamento do ambiente da escola, para se aproximar do ambiente exterior. O ambiente exterior possui arvores e vegetação e na escola somente grama. Assim podemos pensar em ambientes restauradores para as crianças no ambiente escolar. 


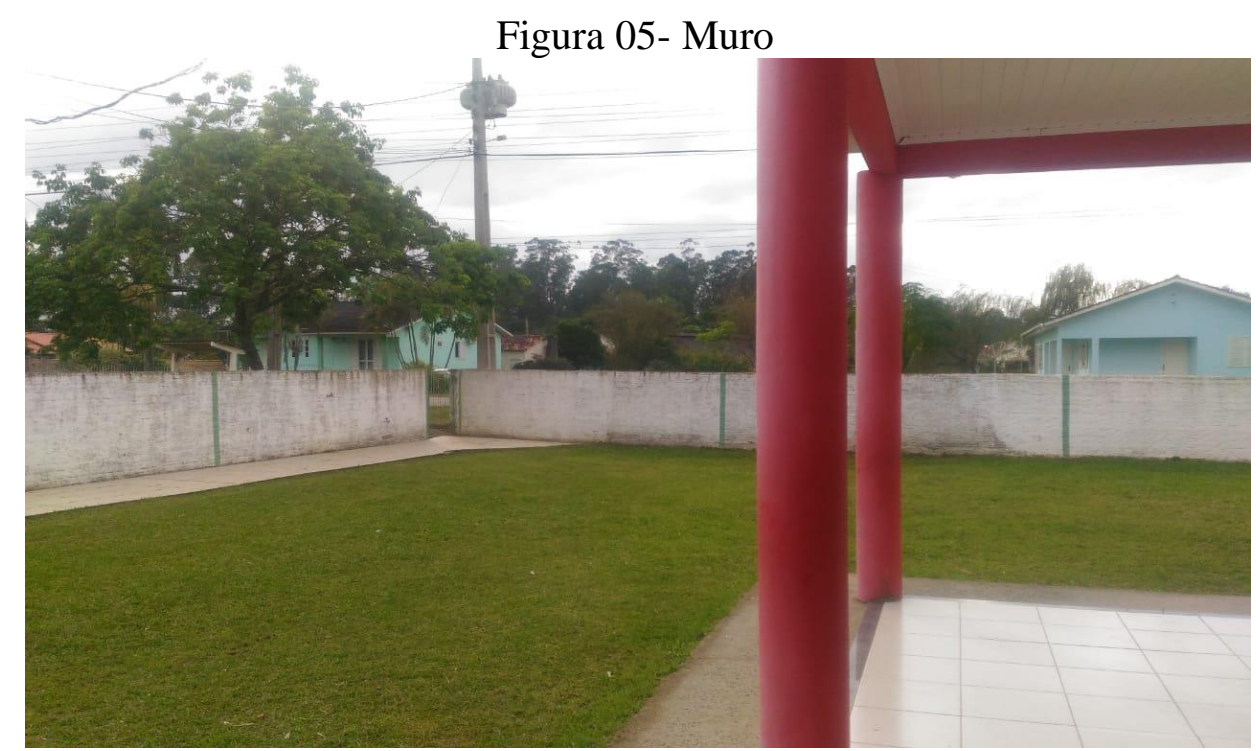

Fonte: Das autoras.

Vivenciamos uma sobrecarga da atenção devido aos ambientes construídos que são ricos em estímulos que exigem o direcionamento da atenção, o que mobiliza a atenção direcionada de forma demasiada (SBISSA, 2009). Quando a atenção da criança diminui, a mesma passa a apresentar maior dificuldade em lidar com situações estressantes, sendo necessário que ocorra uma restauração dessa capacidade (CORRALIZA; COLLADO; BETHELMY, 2012).

A capacidade restauradora dos lugares também atua sobre a preferência ambiental (HIETANEN; KORPELA, 2004), ou seja, pessoas tendem a preferir lugares que possibilitam a restauração da atenção, como forma de garantir a satisfação de suas necessidades - o que explica, no contexto escolar, a preferência por pátios e ginásios esportivos, espaços que recuperam do esforço de atenção da sala de aula.

Por essa razão, ambientes restauradores na escola, que promovam conforto, sensações agradáveis e identificação, também contribuem para a promoção de vínculos afetivos com o lugar, visto que um julgamento positivo deste frente à satisfação das necessidades da pessoa descreve um dos possíveis processos formadores de apego (GIULIANI, 2003, 2004)

Quando chegou 9h40min o sinal bateu anunciando que é horário de ir ao banheiro, escovar os dentes, tomar agua e ir para a sala. Os alunos que brincavam de lego começaram a guardar e seus amigos que não estavam ali também ajudaram. Alguns foram para a fila da 
água, outros para o banheiro escovar os dentes. Quando chegou 9:49 todos os alunos já haviam entrado na sala.

Percebe-se o tempo curto nas brincadeiras e a alternância entre uma atividade e outra, onde os alunos querem aproveitar o tempo para fazer o máximo de atividades e brincadeiras.

No segundo momento, a professora da classe escolheu três alunos que vinham de diferentes meios de locomoção para participar da segunda etapa, que tem como objetivo através de desenhos, com o tempo de 10min para faze-los, identificar os níveis de apropriação do ambiente.

Antônio e Guimarães (2005) argumentam que o desenho infantil é mais que uma simples imagem para a criança, pois nele materializa-se seu inconsciente, registrando, na folha de papel, elementos da sua vida cotidiana: uma representação simbólica, abrangendo uma relação de identidade com o que simboliza, apresentando uma teia de significações do seu pensamento tanto objetivo como subjetivo.

Após o termino do desenho, foi realizado uma conversa separada com cada um dos participantes, onde eles descreveram o desenho.

Figura 06 - Desenho Kauan

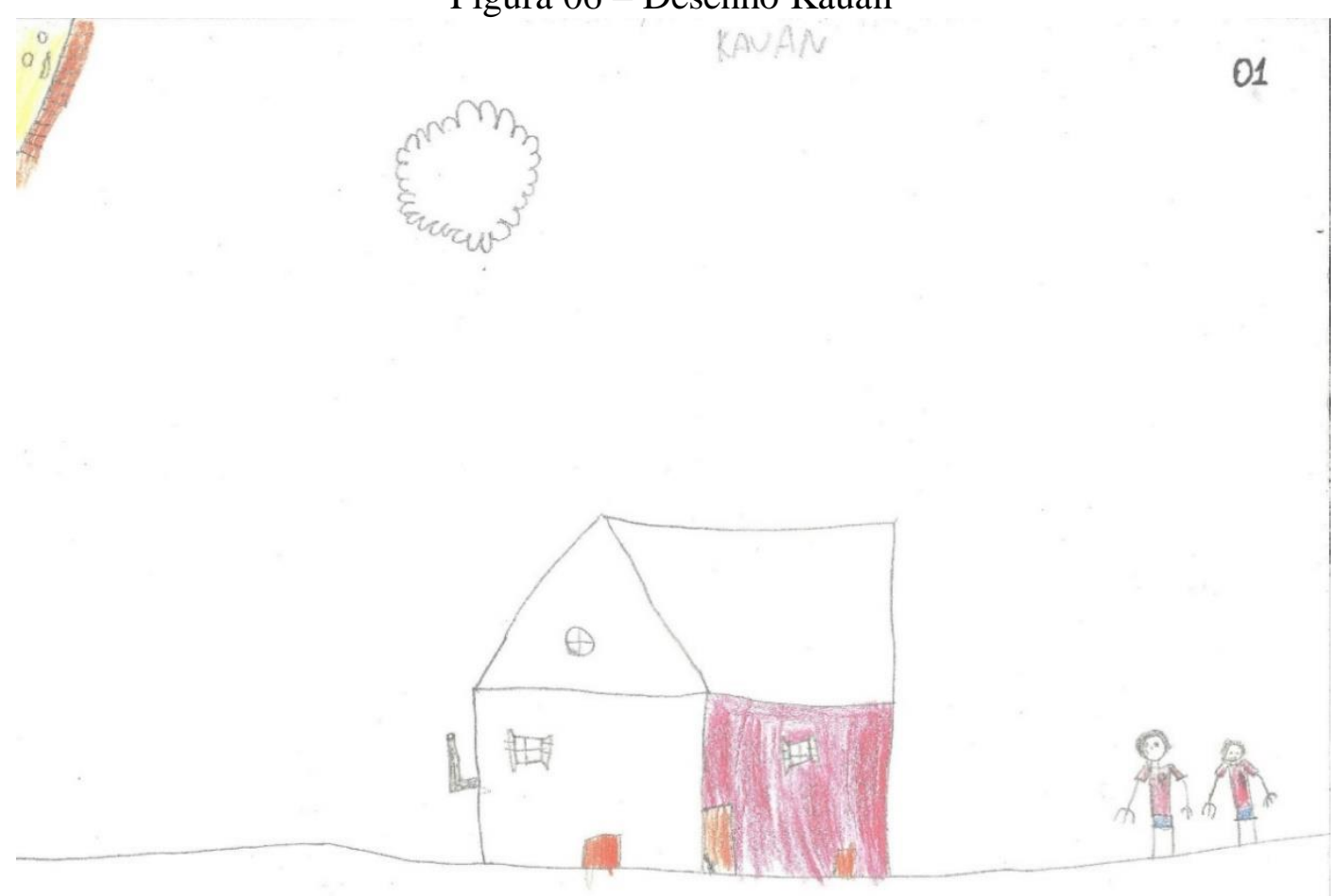

Fonte: Das autoras. 
Kauan - Desenha a sua casa e ele e seu irmão esperando o ônibus. Diz que mora longe da escola, e que todos os dias ele e seu irmão mais velho esperam o ônibus para vir para escola, ele afirma que gosta de vir para a escola. No desenho a casa é o elemento principal, ele a descreve, o fogão a lenha que ele tem em casa, ele diz que ele é quem fica mais perto desse fogão porem a mãe dele está lá quando faz a comida, ou seja, ele não representou a mão objetivamente, mas ela está ali, na chaminé do fogão a lenha. Percebe-se então o enfoque do desenho na casa e não no caminho, sendo assim, sua consciência espacial, possivelmente não está sendo potencializada.

Figura 07- Desenho $\mathrm{M}^{\mathrm{a}}$ Eduarda

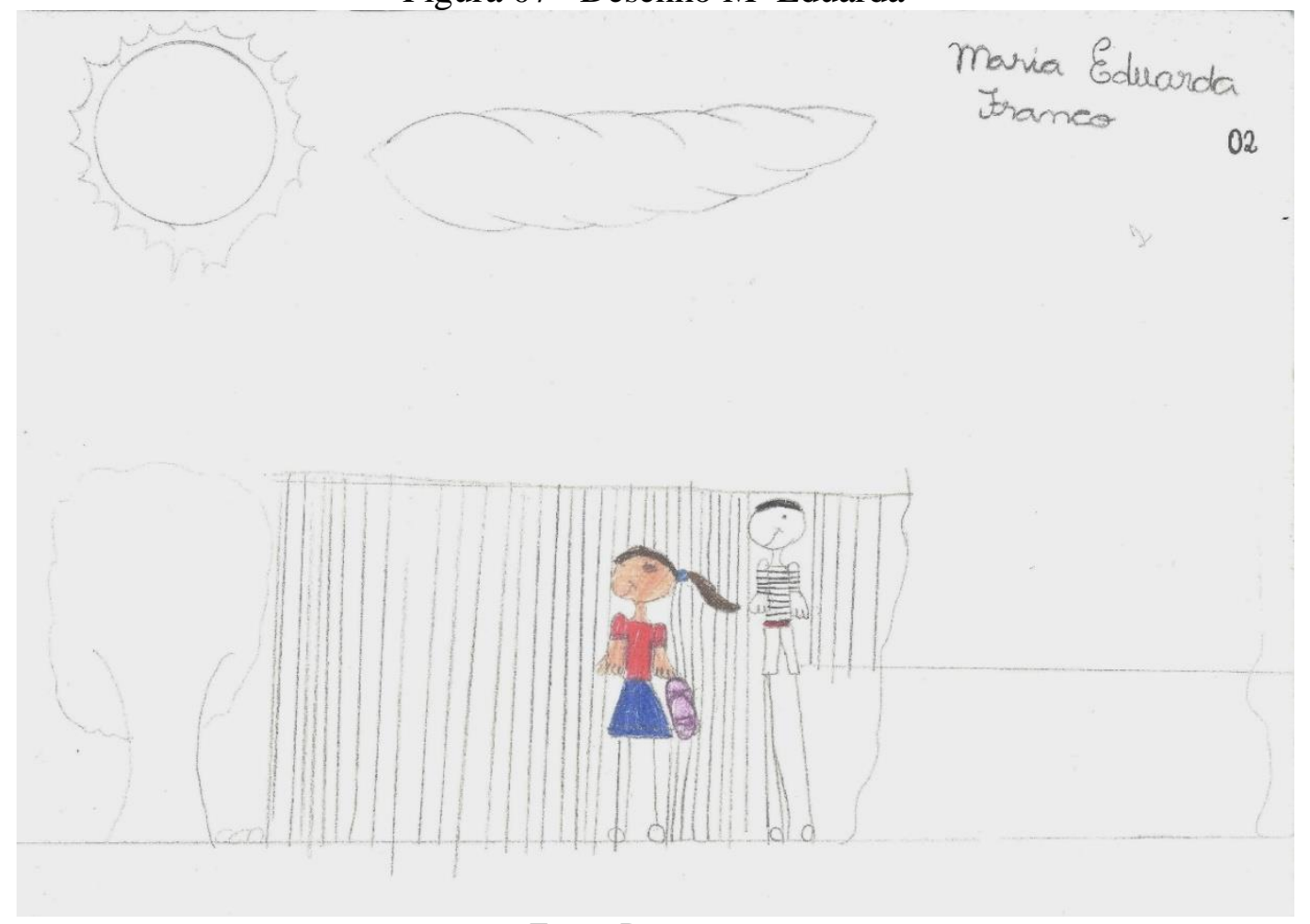

Fonte: Das autoras.

Maria Eduarda - Ela vem a pé para a escola, mora a alguns metros de distância. Seu pai ou sua mãe sempre a trazem para a escola, e na volta sua irmã vem junto busca-la. Ela conhece as casas, os animais que o vizinho tem, os pés de laranjeira que ela e seus amigos brincavam enquanto estavam na educação física da escola, que agora foi proibido subir. Ela fala que gosta de vir com seu pai pois nesse caminho eles aproveitam para conversar sobre a escola e as tarefas. Descreve também a rua que leva até as casas perto da sua, descreve o caminho, fala o que tem nas casas, os galpões e a lavação. Ela conta que não morava ali anteriormente, e usava o ônibus para ir para a escola, que era legal também pois tinha amigos 
para conversar. No desenho o principal elemento o caminho, mostrando maior consciência ambiental, isso, provavelmente, porque vem até a escola caminhando, e por motivos que ela afirmou de ir toda semana com seu pai até os lugares próximos de a pé ou de bicicleta.

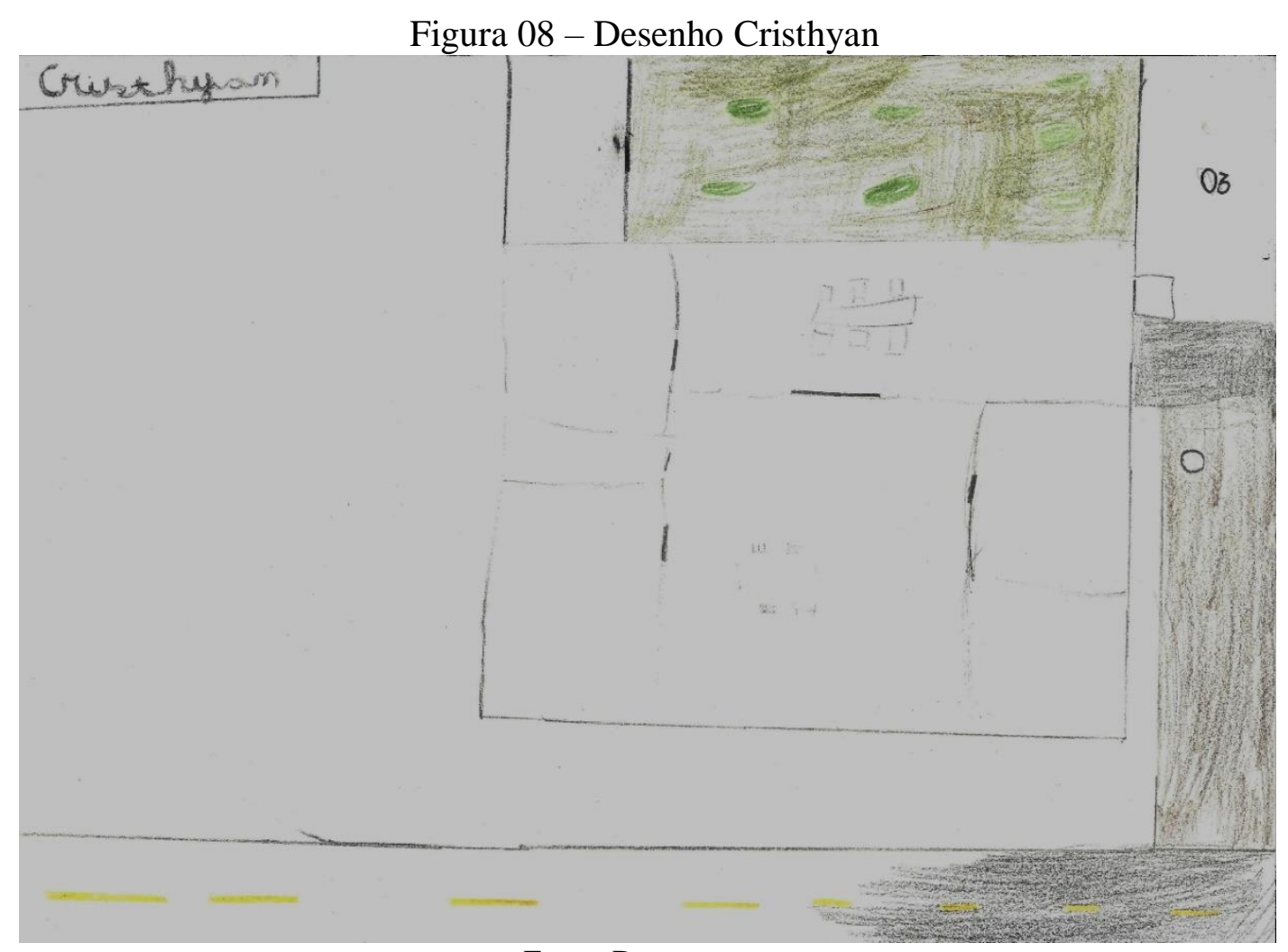

Fonte: Das autoras.

Cristhyan - Ele vem de carro até a escola com sua mãe, ele descreve o seu caminho até a escola quando está no carro, ele conhece o viaduto a rotatória e as lojas por onde passa, porém, a parte mais legal é a volta de ônibus, pois tem seus amigos, o motorista e pode conversar com eles. Na conversa percebe-se que ele não tem amigos para brincar em volta de casa, e por isso brinca muito com seus cachorros. Ele ajuda no serviço de casa, porem fala que sua mãe tem que levar ele a escola pois é a única que resta, seu pai, seu avô e sua avô estão sempre trabalhando. Ele conta que gosta muito da escola pois ele quer se tornar igual sua mãe que é muito inteligente. $\mathrm{O}$ enfoque que ele quis dar no seu desenho foi o tamanho da sua casa em comparação com o tamanho do seu espaço de lazer, o pátio dos animais é grande e ele gostaria de usa-los para brincar lá também.

Meinig (2002), mostra as múltiplas facetas que uma única paisagem/ desenho pode ter e apresenta "o olho que observa" através de dez diferentes observações de uma mesma paisagem, chegando à conclusão de que "qualquer paisagem é composta não apenas por 


\section{ANÁLISE DO APEGO AO LUGAR E REPRESENTACÕES SOCIAIS DA ESCOLA EM CRIANÇAS NO ÂMBITO ESCOLAR}

aquilo que está à frente de nossos olhos, mas também por aquilo que se esconde em nossas mentes" (idem, p.35).

As análises foram feitas a partir do desenho e da fala, identificando os pontos principais, e como resultado pode-se perceber que o diferente tipo de locomoção e os costumes de cada um influenciam no amadurecimento da percepção ambiental, tendo em vista que aquela que ia a pé para a escola conseguiu descrever todo o caminho que percorre com detalhes, comparando com o que ia de ônibus não conseguiu pensar no caminho e enfatizou a casa no seu desenho e fala.

\section{CONCLUSÃO}

A criança na fase do ensino fundamental desenvolve sua percepção do mundo, suas relações pessoais, o reconhecimento da sua identidade, e fatores como a qualidade do ambiente escolar, a disposição de mobiliário e brinquedos, influenciam diretamente na aprendizagem e no desenvolvimento da criança. Dessa forma, neste ambiente escolar onde as crianças andavam em pé pode-se haver a colocação de bancos para criar um estar para conversar; nas áreas de piso concreto não utilizada pode-se desenhar amarelinhas ou a colocação de brinquedos como balanço ou roda-roda para aumentar os tipos de brincadeiras que as crianças podem realizar enquanto estão no momento livre da escola.

Compreende-se que o meio de locomoção da criança até a escola e seus hábitos fazem com que a sua percepção ambiental aumente ou não. Ao caminhar a pé a criança consegue focar sua atenção na paisagem, nos elementos e na composição do caminho que está fazendo, fazendo com que ela tenha mais domínio do ambiente possibilitando maior auto segurança no momento que, por exemplo, ela é deixada na escola, pois ela saberá fazer o caminho de volta até a casa caso algo aconteça. Para que essa percepção ambiental aumente não só nos alunos que fazem o trajeto até a escola a pé, sugere-se que haja atividades na escola que façam a criança focar a atenção nos elementos que estão ao redor na paisagem externa, com isso a criança iria perceber coisas que ela não percebe quando está brincando ou fazendo alguma atividade na área externa.

Conseguiu-se analisar o apego ao lugar e as representações sociais para as crianças principalmente aquelas que fizeram parte da segunda etapa. Pelos desenhos podemos observar quem fica em primeiro e segundo plano para a criança. Com isso, para que a escola seja um local agradável para a criança e ela se sinta parte do ambiente precisa-se que ela forneça elementos para apropriação do espaço, para que ela possa também construir esse ambiente e 
se identificar, como exemplos: oficina de pintar o muro da escola; fazer um mural com desenhos e/ou fotos delas; participar na construção de uma horta para a escola. Com isso o nível de apego ao ambiente irá aumentar e a criança se sentirá mais segura aumentando o auto controle dela sobre lugar.

\section{REFERÊNCIAS}

ANTONIO, D. G. \& GUIMARÃES, S. T. L. Representações do meio ambiente através do desenho infantil: refletindo sobre os procedimentos interpretativos. Rev. Ed. Amb. Emação. $\mathrm{N}^{\mathrm{o}} 14,2005$.

BROWN, B. B.; PERKINS, D. D. Disruptions in place attachment. In 1. Altman \& S. Low, (Eds.), Place attachment (pp. 1--12). 1992.

CAMPOS -DE- CARVALHO, Mara Ignez. Psicologia Ambiental-algumas considerações. Psicologia: Teoria e Pesquisa, v. 9, n. 2, p. 435-447, 2012.

COOPER, R. Introduction to queuing theory. North Holland: Elsevier. 1981.

DAVIS, Claudia. Oliveira. Psicologia na educação. São Paulo: Cortez, 1993.

CORDIOLI, A.; TERUCHKIN, B. Fobias específicas. Acesso em 28.03.2007. Disponível em http://www.ufrgs.br/psiq/TCCfesp.html.

CORRALIZA, José A.; COLLADO, Silvia; BETHELMY, Lisbeth. Nature as a moderator of stress in urban children. Procedia-Social andBehavioralSciences, v. 38, p. 253-263, 2012.

GIULIANI, M. V. O lugar do apego nas relações pessoas-ambiente.

In E. T. O. Tassara, E. P. Rabinovich\& M. C. Guedes (Orgs.), Psicologia e ambiente (pp.89106). São Paulo: Educ. 2004.

GIULIANI, M. V. Theory of attachment and place attachment. In: BONNES, M.; LEE, T.; BONAIUTO, M. (Orgs.). Psychological theories for environmental issues. Aldershot: Ashgate, 2003, p. 137-170.

HIETANEN, Jari K.; KORPELA, Kalevi M. Do both negative and positive environmental scenes elicit rapid affective processing?.Environment and Behavior, v. 36, n. 4, p. 558-577, 2004.

ITTELSON, W. H., PROSHANSKY, H. M., \& RIVLIN, L. G. The environmental psychology of the psychiatric ward. In H. M. Proshansky, W. H. Ittelson\& L. G. Rivlin, (Orgs.), Environmental psychology: Man and his physical setting (pp. 419-439). Nova York: Holt, Rinehart \& Winston, 1970.

JODELET, D. Les ReprésentationsSociales. Paris: PUF; 1989. Représentationssociales: um domaine en expansion, p. 31-61. 
LACAN, Jacques. O estádio do espelho como formador da função do eu. J. Lacan, Escritos, p. 96-103, 1988.

MEINIG, Donald W. O olho que observa: dez versões da mesma cena. Espaço e cultura, n. $16,2003$.

MELO, Rosane Gabriele C. de. Psicologia ambiental: uma nova abordagem da psicologia. Psicologia USP, v. 2, n. 1-2, p. 85-103, 1991.

MORAN, José Manuel. Novas tecnologias e mediação pedagógica. Papirus Editora, 2000.

MOSER, Gabriel. Psicologia ambiental. Estudos de psicologia (Natal), v. 3, n. 1, p. 121-130, 1998.

PROSHANSKY, Harold M.; ITTELSON, William H.; RIVLIN, Leanne G. (Ed.).

Environmental psychology: Man and his physical setting. New York: Holt, Rinehart and Winston, 1970.

RIVLIN, Leanne G. Olhando o passado e o futuro: revendo pressupostos sobre as interrelações pessoa-ambiente. Estudos de Psicologia (Natal), v. 8, n. 2, p. 215-220, 2003.

SBISSA, P. P. M. Desenvolvimento da atenção como mecanismo restaurador da saúde. In: A. Kuhnen, R. M. Cruz, \& E. Takase (Org), Interações pessoa-ambiente e saúde (pp.261-275). São Paulo: Casa do Psicólogo, 2009.

SHUMAKER, Sally A.; TAYLOR, Ralph B. Toward a clarification of people-place relationships: A model of attachment to place. Environmental psychology: Directions and perspectives, v. 2, p. 19-25, 1983.

SOMMER, Robert. Espaço pessoal. São Paulo: EPU, 1973.

STOKOLS, Daniel. Environmental psychology. Annual review of psychology, v. 29, n. 1, p. 253-295, 1978. 